\title{
Results of 20 consecutive patients treated with the Repiphysis expandable prosthesis for primary malignant bone
}

\author{
Joseph Benevenia", Francis Patterson, Kathleen Beebe, Kimberly Tucker, Jeffrey Moore, Joseph Ippolito
} and Steven Rivero

\begin{abstract}
Limb-salvage for primary malignant bone tumors in pediatric patients presents a unique challenge when resection includes an active physis. Early expandable prostheses required open surgical procedures to achieve lengthening. Newer prostheses are capable of achieving expansion without open procedures through the use of an electromagnetic field. This study reports our results with 90 consecutive expansion procedures using the Repiphysis ${ }^{\circledR}$ prosthesis. We retrospectively reviewed the records of 20 patients (22 limbs) who underwent limb-salvage using the Repiphysis ${ }^{\circledR}$ prosthesis from 2003 to 2015. There were 9 males and 11 females with a mean age of 9 years and 9 months (6-16 years). Reconstruction included the distal femur in 11 cases, total femur in four, proximal tibia in three, proximal humerus in three, and total humerus in one. Complications were reviewed and functional scores were recorded using the MSTS/ISOLS system. Five patients had a second prosthesis implanted during the course of the study for a total of 27 prostheses. The mean follow-up was 57 (6-148) months. Four patients have not been expanded: three due to death prior to lengthening, and one patient who has not yet developed a leg length discrepancy. Ninety consecutive expansion procedures were performed in 18 limbs in 16 patients. A mean of $9(5-20) \mathrm{mm}$ was gained per expansion and $4.8 \mathrm{~cm}$ per patient who has undergone expansion to date. Seven patients have reached skeletal maturity and have been converted to an adult endoprosthesis. These patients averaged 8 expansions per patient and a mean of 7.4 $(1.8-12.9) \mathrm{cm}$ in length gained. There were 15 complications in 11 patients including one dislocation, one contracture, four cases of aseptic loosening, five structural failures (three expansion mechanism failures and two tibial fractures), three deep infections, and one case of local recurrence. The mean MSTS score was $80 \%$ (37-97\%) and the limb retention rate was $95 \%$. The results of this study are comparable to previous studies involving non-invasive prostheses. This study hopefully provides additional data for clinicians to consider when faced with limb threatening sarcomas in the immature skeleton.
\end{abstract}

Keywords: Orthopaedic surgery, Musculoskeletal oncology, Expandable endoprosthesis

\section{Background}

Limb salvage became popularized following detailed reports by Mankin and Marcove in 1976 (Mankin et al. 1976; Marcove 1976). These papers, in conjunction with the classic report by Simon and Rougraff showing no survival or local control advantage to amputation, paved

*Correspondence: benevejo@njms.rutgers.edu

Department of Orthopaedic Surgery, Rutgers New Jersey Medical School, 140 Bergen Street, ACC Building, Suite D-1610, Newark, NJ 07103, USA the way for limb preservation procedures (Rougraff et al. 1994).

Limb-salvage in pediatric patients poses an additional challenge compared to adults due to the presence of an open physis. In order to obtain a wide surgical margin, the growing physis must often be removed, creating a limb-length discrepancy. Lewis published one of the first reports on the use of expandable endoprostheses to help minimize limb length discrepancy (Lewis 1986; Kenan and Lewis 1991). These designs incorporated the use of a screw extension mechanism, where a chuck key would

\section{望 Springer}

(c) 2015 Benevenia et al. This article is distributed under the terms of the Creative Commons Attribution 4.0 International License (http://creativecommons.org/licenses/by/4.0/, which permits unrestricted use, distribution, and reproduction in any medium, provided you give appropriate credit to the original author(s) and the source, provide a link to the Creative Commons license, and indicate if changes were made. 
be inserted through an incision to expand the length of the prosthesis and thus the extremity, while later methods utilized modular body segments to achieve lengthening, requiring open surgical procedures (Lewis 1986; Kenan and Lewis 1991; Eckardt et al. 2000; Neel and Letson 2001). Jeys reported on periprosthetic infections in orthopaedic oncology conditions and found the use of expandable prostheses in children as a significant risk factor with a rate of $18 \%,(\mathrm{p}=0.007)$, and that infection was increased as much as $5 \%$ per lengthening procedure (Jeys et al. 2005). In order to accurately address limb surgery in children with sarcomas the authors feel they should mention two other techniques, amputation and arthroplasty. The former has few surgical side effects with decreased functional scores (Eckardt et al. 1985; Simon et al. 1986). Rotationplasty in the growing child has excellent function with few surgical complications (Hardes et al. 2003). Acceptance of the physical appearance of this option has limited its use (Veenstra et al. 2000).

The Repiphysis ${ }^{\circledR}$ non-invasive expandable prosthesis (Microport Orthopedics, Arlington, Tennessee, USA, originally manufactured as the Phenix prosthesis, Phenix Medical, Paris, France) was the first endoprosthesis design to introduce the concept of a non-invasive expansion procedure involving the use of an electromagnetic field (Wilkins and Soubeiran 2001; Neel et al. 2003; Gupta et al. 2006). This implant allows for a serial number of lengthenings to be performed without an open surgical procedure. The closed lengthenings avoid incisions. This in turn avoids all those problems associated with open surgery, blood loss and acute lengthenings. Acute lengthenings with sudden elongation, may produce neuropathy, vascular compromise, and contracture (Herzog and Hefti 1992; Janovec and Polách 1990) The aim of the current study is to report our experience with 20 patients treated with the Repiphysis ${ }^{\circledR}$ non-invasive expandable prosthesis for limb-salvage.

\section{Methods}

We retrospectively reviewed the records of 20 consecutive patients who underwent implantation of the Repiphysis ${ }^{\circledR}$ noninvasive expandable prosthesis at our institution from 2003 to 2015. Minimum follow-up was 14 months unless patients died of disease or the implant failed prior. We have previously reported on early results of the first 12 of these patients and present them with longer term follow-up and additional lengthening procedures (Beebe et al. 2010) in addition to eight new patients. Data collected included patient demographics, pathology, lengthening, total expansion length, complications, and functional status. Implantation of the Repiphysis ${ }^{\circledR}$ prosthesis is indicated for limb-salvage in skeletally immature patients in which wide resection includes removal of an active physis and the patient is left with a projected limb-length discrepancy of $\geq 6 \mathrm{~cm}$ (Harvey et al. 2010; Holm et al. 1994; Papaioannou et al. 1982; Song et al. 1997; Stanitski 1999). Growth remaining was determined according to the standard methods after bone age was assessed (Anderson et al. 1963; Dimeglio 2001). For use in the humerus, the Repiphysis ${ }^{\circledR}$ was discussed with the patient and family as a limb-salvage option and Compassionate Use Guidelines were followed with our Institutional Review Board (IRB) permission. Patients were indicated for expansion when chemotherapy was complete and a limb-length discrepancy of $\geq 1 \mathrm{~cm}$ was noted clinically. Functional scores were recorded using the MSTS/ISOLS functional scoring system (Enneking et al. 1993). Scores were obtained upon completion of rehabilitative therapy, or at most recent follow-up if therapy was not completed.

When the prosthesis is exposed to an external ring producing an electromagnetic field, the heat softens the outer polyethylene cylinder, thus unlocking the flared trumpet and permitting the prosthesis to expand as the spring decompresses and allows the inner tube to slide within the polyethylene cylinder (Wilkins and Soubeiran 2001) All expansions are performed with conscious sedation or general anesthesia in the operating room with fluoroscopic guidance, using a $\mathrm{C}$-arm, radiolucent table, radiolucent ruler, and goniometer. Expansion procedures typically take $20 \mathrm{~min}$. The radiofrequency signal is applied in pre-set "pulses" under fluoroscopic guidance until the desired lengthening is achieved. Upon conclusion of the lengthening, the metallic trumpet cools down and locks the prosthesis back in place in a new portion of the polyethylene cylinder (Fig. 1a, b).

\section{Results}

The results are summarized in Table 1 . Twenty patients had 22 sites treated with 27 non-invasive expandable endoprostheses from 2003 to 2015 . Two patients (16 and 20) had a second osteosarcoma: 1 in the contralateral femur, 1 in the ipisilateral humerus. The diagnosis was osteosarcoma in 18 patients and Ewing's sarcoma in two. There were 9 males and 11 females studied with a mean age of 9 years and 9 months (6-16 years) at the index procedure and a mean follow-up of 57 (6-148) months, with an endpoint of death or latest follow-up. Of 22 limbs in 20 patients, 17 were treated at the author's institution primarily with Repiphysis. Two patients (14 and 17) were treated at outside institutions and presented to our institution after a failed implant. One patient had an earlier invasive expandable prosthesis prior to the availability of Repiphysis, which was explanted following deep infection from an open lengthening. This patient then had a Repiphysis implanted following eradication of infection 


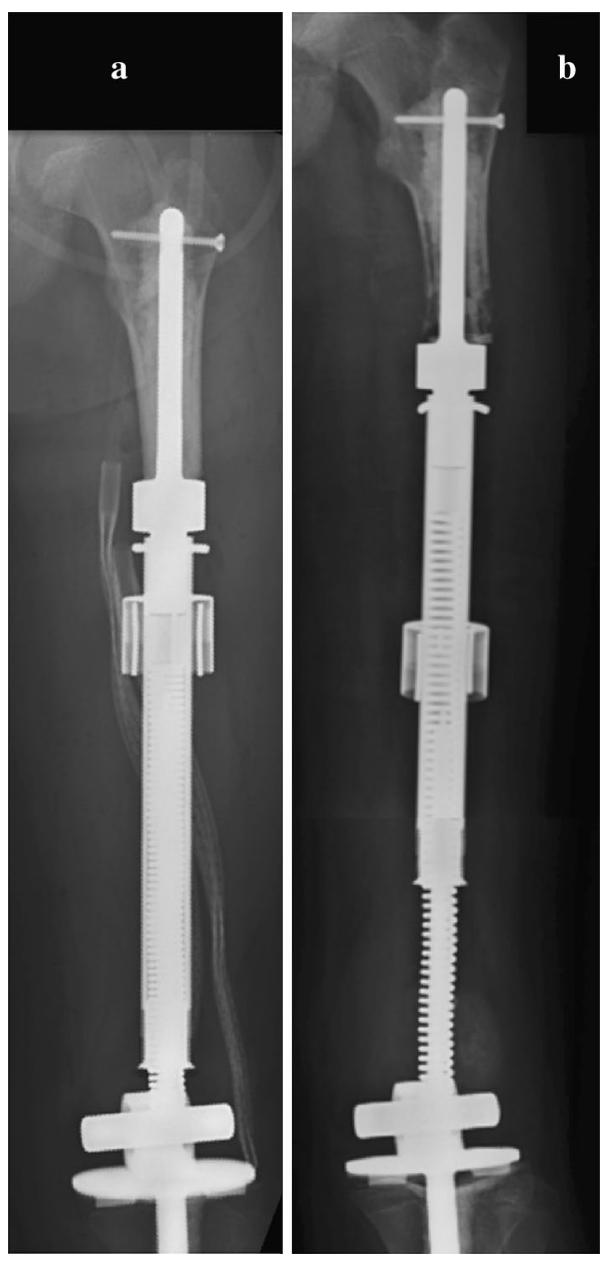

Fig. 1 Patient with a femoral prosthesis prior to undergoing any expansion procedures (a) and at the maximum growth potential for the implant (b)

(patient 7). One patient initially had an intercalary allograft, which fractured and was revised with a Repiphysis (patient 16a).

Reconstruction included the distal femur in 11 cases, total femur in four, proximal tibia in three, proximal humerus in three, and total humerus in one. Five patients had a second endoprosthesis implanted during the study period for a total of 27 non-invasive expandable prostheses in our 20 patient cohort. Of these five second implants, one was for a deep infection in which the original Repiphysis ${ }^{\circledR}$ was removed and a new one reimplanted after eradication of the infection (Patient 13), and four implants were exchanged for a new prosthesis after they had reached their maximum elongation to permit continued expansion (Patients 9, 14, 15 and 16a). Generally the authors waited until the patient required an expansion or the implant became symptomatic before explant and re-implantation of a second new prosthesis.
At the time of latest follow-up, $65 \%$ of patients are alive (11 CDF, 7 DOD, 1 AWD, 1 NED). Ninety consecutive expansion procedures were performed in 18 limbs in 16 patients. The patients who have not had any expansions include three patients who died of disease prior to lengthening (Patients 8, 11 and 17) and one patient who has not yet established a limb-length discrepancy warranting expansion (Patient 19). Two patients $(14,15)$ had a second prosthesis that underwent additional expansion. A mean of 9 (5-20) $\mathrm{mm}$ was gained per expansion and $4.8 \mathrm{~cm}$ per patient who has undergone expansion to date.

\section{Conversion to adult implants}

Among the prostheses which have undergone expansion: eight are still undergoing expansion procedures, three patients have died of disease prior to reaching skeletal maturity (Patients 3, 10 and 13), and seven patients have reached skeletal maturity and been converted to a nonexpandable adult endoprosthesis (Patients 1, 2, 4, 5, 12, 14, and 15) (Fig. 1c). Among those who have reached skeletal maturity, there were an average of 8 expansions per patient and a mean length gained of $7.4(1.8-12.9) \mathrm{cm}$. Six of the seven patients have no limb length discrepancy. The seventh patient had a proximal humerus replacement, which experienced an expansion mechanism failure (Fig. 2). Because the patient was nearing skeletal maturity, revision included conversion to an adult endoprosthesis. The patient has a $2.5 \mathrm{~cm}$ limb length discrepancy, which is not clinically symptomatic, with an MSTS score of $87 \%$ (Patient 12).

During the course of our study period we experienced 15 complications (56\%). We classified our complications according to the five modes of failure for tumor endoprostheses (Henderson et al. 2011; Palumbo et al. 2011) (Table 2). There were two type I (soft-tissue) failures. A patient with a distal femoral prosthesis underwent an arthroscopic release of the quadriceps due to an extensor mechanism contracture (Patient 5). Another patient had initially presented with a custom expandable humeral prosthesis that became infected and was treated with an explant, IV antibiotics, and a spacer followed by re-implantation using a Repiphysis ${ }^{\circledR}$. The Repiphysis ${ }^{\circledR}$ elbow became stiff after six lengthenings, with a flexion contracture and a proximal radial-ulnar joint dislocation resulting from previous proximal ulnar physeal arrest, secondary to infection (Patient 7, Fig. 3). There were four type II (aseptic loosening) failures in which there was evidence of loosening of the stem of the prosthesis, occurring at a mean of 50.5 (23-83) months after initial surgery (Patients 1, 2, 15 and 16a, Fig. 4). Two of these were at skeletal maturity and revised with an adult prosthesis, and the other two were revised with a second Repiphysis $^{\circledR}$. Five patients experienced a type III (structural) failure. There were three failures of the expansion 
Table 1 Overview of patient characteristics, lengthening, and complications

\begin{tabular}{|c|c|c|c|c|c|c|c|c|c|c|c|c|}
\hline Pt. & $\begin{array}{l}\text { Age } \\
\text { at Initial } \\
\text { surgery } \\
(Y+M)\end{array}$ & Diagnosis & Stage & $\begin{array}{l}\text { Location } \\
\text { of lesion }\end{array}$ & $\begin{array}{l}\text { No. } \\
\text { of exp }\end{array}$ & $\begin{array}{l}\text { Length } \\
\text { gained } \\
(\mathrm{cm})\end{array}$ & $\begin{array}{l}\text { Follow- } \\
\text { up } \\
\text { (months) }\end{array}$ & $\begin{array}{l}\text { Converted } \\
\text { to adult } \\
\text { prosthesis? }\end{array}$ & $\begin{array}{l}\text { Type } \\
\text { of } \\
\text { failure }\end{array}$ & $\begin{array}{l}\text { Onco. } \\
\text { status }\end{array}$ & Complications & $\begin{array}{l}\text { MSTS } \\
\text { score } \\
(\%)\end{array}$ \\
\hline 1 & $9+8$ & Osteosarcoma & $\| B$ & R Prox Tibia & 2 & 1.8 & 144 & Yes & $\|$ & CDF & Aseptic loosening & 93 \\
\hline 2 & $9+10$ & Osteosarcoma & $\| B$ & R Dist Femur & 10 & 10 & 148 & Yes & $\|\|$, & NED & $\begin{array}{l}\text { Aseptic loosening } \\
\text { and tibial fracture }\end{array}$ & 77 \\
\hline 3 & $9+11$ & Osteosarcoma & $\| \mathrm{B}$ & R Dist Femur & 1 & 2 & 22 & No & & DOD & & 67 \\
\hline 4 & $8+10$ & Osteosarcoma & $\| \mathrm{B}$ & $\begin{array}{l}\text { LProx } \\
\text { Humerus }\end{array}$ & 6 & 5.8 & 116 & Yes & & CDF & & 93 \\
\hline 5 & $11+2$ & $\begin{array}{l}\text { Ewing's Sar- } \\
\text { coma }\end{array}$ & $\| B$ & L Dist Femur & 8 & 7.9 & 137 & Yes & I, IV & CDF & $\begin{array}{l}\text { Contracture, infec- } \\
\text { tion }\end{array}$ & 97 \\
\hline 6 & $10+8$ & Osteosarcoma & $\| B$ & L Dist Femur & 6 & 7 & 61 & No & & CDF & & 77 \\
\hline 7 & 16 & $\begin{array}{l}\text { Ewing's Sar- } \\
\text { coma }\end{array}$ & $\| B$ & $\begin{array}{l}\text { LProx } \\
\text { Humerus }\end{array}$ & 6 & 5.5 & 75 & No & I & CDF & $\begin{array}{l}\text { Contracture/dislo- } \\
\text { cation }\end{array}$ & 93 \\
\hline 8 & $7+9$ & Osteosarcoma & $\| \mathrm{B}$ & L Dist Femur & 0 & 0 & 10 & No & & DOD & & 70 \\
\hline $9^{A}$ & $12+1$ & Osteosarcoma & $\| \mathrm{B}$ & L Prox Tibia & 5 & 4.5 & 64 & No & $\| I \mid \times 2$ & DOD & $\begin{array}{l}\text { Prosthesis failure, } \\
\text { tibial fracture }\end{array}$ & 93 \\
\hline 10 & $10+6$ & Osteosarcoma & III & L Dist Femur & 2 & 2.2 & 27 & No & & DOD & & 80 \\
\hline 11 & $12+9$ & Osteosarcoma & $\| \mathrm{B}$ & L Dist Femur & 0 & 0 & 12 & No & V & DOD & Hip disarticulation & 80 \\
\hline 12 & 7 & Osteosarcoma & $\| B$ & $\begin{array}{l}\text { LProx } \\
\text { Humerus }\end{array}$ & 8 & 6.9 & 71 & Yes & III & CDF & & 87 \\
\hline $13^{\mathrm{A}}$ & $9+7$ & Osteosarcoma & $\| B$ & L Dist Femur & 4 & 4 & 41 & No & IV & DOD & Infection & 63 \\
\hline $14^{A, C}$ & $9+11$ & Osteosarcoma & $\| B$ & L Dist Femur & 9 & 6.8 & 67 & Yes & III, IV & CDF & $\begin{array}{l}\text { Prosthesis failure, } \\
\text { Infection }\end{array}$ & 87 \\
\hline $15^{\mathrm{A}}$ & $9+4$ & Osteosarcoma & $\| B$ & L Dist Femur & 14 & 12.9 & 63 & Yes & $\|$ & CDF & Aseptic loosening & 90 \\
\hline $16 a^{A}$ & $9+2$ & Osteosarcoma & $\| B$ & R Dist Femur & 1 & 1 & 54 & No & $\|$ & CDF & Aseptic loosening & 93 \\
\hline $16 b$ & 11 & Osteosarcoma & $\| \mathrm{B}$ & L Dist Femur & 1 & 1 & 30 & No & & CDF & & 83 \\
\hline $17^{C}$ & 12 & Osteosarcoma & $\| B$ & L Dist Femur & 0 & 0 & 6 & No & & DOD & & 47 \\
\hline 18 & 6 & Osteosarcoma & $\| \mathrm{B}$ & R Dist Femur & 2 & 2 & 30 & No & & CDF & & 90 \\
\hline 19 & $7+1$ & Osteosarcoma & $\| B$ & L Prox Tibia & 0 & 0 & 14 & No & & CDF & & 37 \\
\hline $20 a$ & $6+9$ & Osteosarcoma & $\| B$ & R Dist Femur & 3 & 2.3 & 37 & No & & AWD & & 83 \\
\hline $20 b^{B}$ & $7+6$ & Osteosarcoma & III & $\begin{array}{l}\text { R Prox } \\
\text { Humerus }\end{array}$ & 2 & 1.7 & 17 & No & & AWD & & 80 \\
\hline
\end{tabular}

Types of failure: soft-tissue (I), aseptic loosening (II), structural failure (III), infection (IV), tumor progression (V)

Patients 1-12 were reported on in previous study

Patients 16 and 20 had diagnosis of Osteosarcoma at two different sites

$D O D$ dead of disease, NED no evidence of disease, AWD alive with disease, CDF continuously disease free

A Indicates that the patient had second Repiphysis expandable prostheses at same site

${ }^{B}$ Patient presented with a second bone lesion without pulmonary metastasis

C Indicates patients initially treated at an outside institution, and presented to our institution after failed implant

mechanism of the prosthesis (Patients 9, 12 and 14). Patients 9 and 12 were converted to an adult prosthesis and patient 14 was revised to a second Repiphysis ${ }^{\circledR}$. The other two type III failures were periprosthetic tibial fractures, which were managed non-operatively (Patients 2 and 9, Fig. 5a-d). Three patients experienced a type IV (infection) failure (Patients 5, 13, and 14, Fig. 6a). These were treated by removal of the implant and placement of a custom antibiotic spacer (Fig. 6b-d), IV antibiotics for six weeks, then oral antibiotics for an additional six weeks, with subsequent re-implantation upon eradication of the infection. One of these patients had a second
Repiphysis ${ }^{\circledR}$ re-implanted (Fig. 6e), and the other two were converted to an adult prosthesis. All of these patients were able to achieve limb length equality. Finally, one patient who did not have any expansions experienced a type-V (tumor progression) failure and required a hip disarticulation (Patient 11). The overall limb preservation rate in our patients was $95 \%$ (21/22 limbs). The mean MSTS score was $80 \%$ (37-97\%).

\section{Discussion}

Over the past 30 years there have been several expandable implant systems designed to be used in the growing 


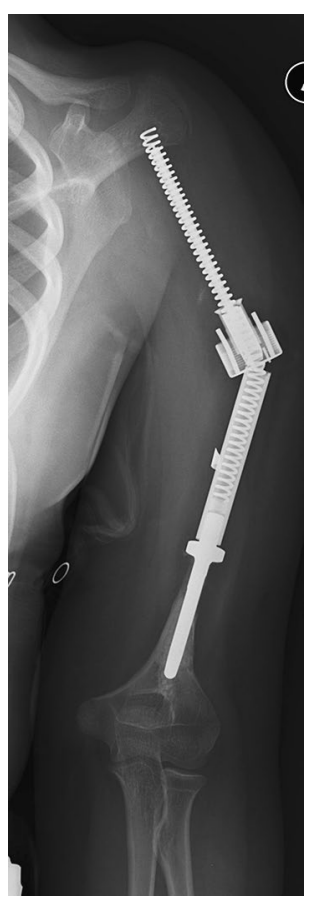

Fig. 2 Breakage of the expansion mechanism in a proximal humeral prosthesis

child. In the 1990's, new prostheses were developed that allowed non-invasive lengthening through the application of an external electromagnetic field (Wilkins and Soubeiran 2001; Neel et al. 2003; Baumgart et al. 1997).

The Repiphysis ${ }^{\circledR}$ prosthesis, originally manufactured as the Phenix ${ }^{\circledR}$ prosthesis in France, was the first of these non-invasive expandable implants used in the United States. Early experience with the prosthesis was reported by Wilkins and Souberian (Wilkins and Soubeiran 2001), who examined the functional outcomes after 21 lengthenings in six patients. One of the major advantages of the Repiphysis ${ }^{\circledR}$ over earlier designs is that the non-invasive nature of the expansion procedure permits frequent expansions of smaller increments with minimal patient discomfort. This decreases the risk of stretch injury to nerves and blood vessels and resection of soft tissue and pseudocapsule around the prosthesis. It avoids an open surgical procedure each time expansion is necessary. Although there were no complications attributed to lengthening procedures themselves, Wilkins and Souberian reported two mechanical complications in one patient (Wilkins and Soubeiran 2001).

In 2003, a multicenter study by Neel et al. (Neel et al. 2003) reported the results of 60 expansions in 18 Repiphysis ${ }^{\circledR}$ prostheses implanted in 15 patients. Mean follow-up was 21.5 (12-33) months. There were no complications associated with lengthening procedures themselves. They had a mean of $3.7 \mathrm{~cm}$ of lengthening and MSTS scores averaging $90 \%$, but the prostheses were subject to a $44 \%$ complication rate including six prosthesis fractures and two aseptic loosenings (Neel et al. 2003). Longer-term studies using the Repiphysis ${ }^{\circledR}$ prosthesis have produced similar results, with mean MSTS scores ranging from 67 to $90 \%$ and patients gaining a mean of 2.5-3.9 cm of lengthening (Saghieh et al. 2010; Cipriano et al. 2015).

The Stanmore Juvenile Tumour System (JTS, Stanmore Implants Worldwide, Stanmore, UK) also incorporates a magnetic field for non-invasive expansion after tumor resection in skeletally immature patients. In contrast to the Repiphysis ${ }^{\circledR}$ design, the JTS contains a magnetic disc, a gearbox, and a power screw embedded within the shaft of the prosthesis. When exposed to an external electromagnetic field the implant is expanded at a fixed rate. One of the limitations of the JTS is that the use of MRI in these patients is contraindicated due to interference with the electromagnetic motor (Gupta et al. 2006).

Hwang et al. reported on the use of the JTS in a series of 25 patients published in 2012 (Hwang et al. 2012). They reported a mean of $3.2 \mathrm{~cm}$ of lengthening with a mean MSTS score of $85 \%$ and a complication rate of $38 \%$. Other studies have reported similar experience with the JTS, with a mean $3.7-4.5 \mathrm{~cm}$ of lengthening, MSTS scores ranging from 82 to $87 \%$, and follow-up of $41.2(22-104)$ and $48(23-146)$ months (Picardo et al. 2012; Henderson et al. 2012).

The current study reports the results of 20 pediatric patients treated at 22 sites with 27 Repiphysis ${ }^{\circledR}$

Table 2 Five modes of tumor prosthesis failure according to Henderson et al. $(2011,2012)$

\begin{tabular}{|c|c|c|}
\hline Type of failure & Description & No. of pts \\
\hline 1 & $\begin{array}{l}\text { Soft-tissue: A functional deficiency of the soft tissue attachments about the implant. Includes instability, tendon rupture, } \\
\text { and wound dehiscence }\end{array}$ & 2 \\
\hline$\|$ & Aseptic loosening: Clinical and radiographic evidence of loosening of the prosthesis & 4 \\
\hline III & $\begin{array}{l}\text { Structural failure: Failure of either the implant or surrounding bone. Includes fractures of the prosthesis, periprosthetic } \\
\text { fractures, and a deficient bony supporting structure }\end{array}$ & 5 \\
\hline IV & Infection: Deep infection requiring removal of the implant & 3 \\
\hline V & Tumor progression: Re-operation due to local tumor recurrence or metastatic disease progression & 1 \\
\hline
\end{tabular}




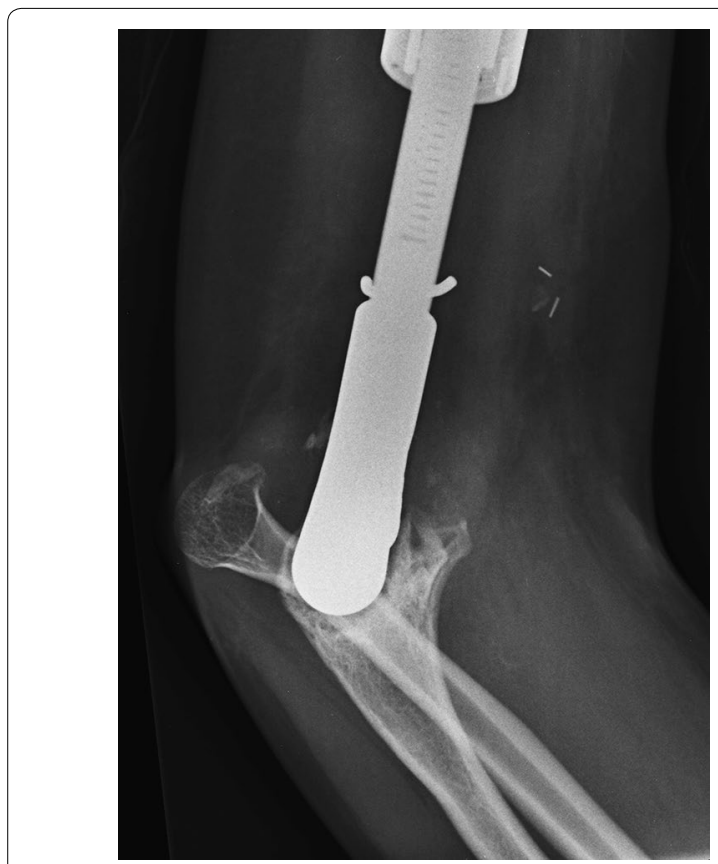

Fig. 3 A contracture/dislocation in a patient with a humeral endoprosthesis

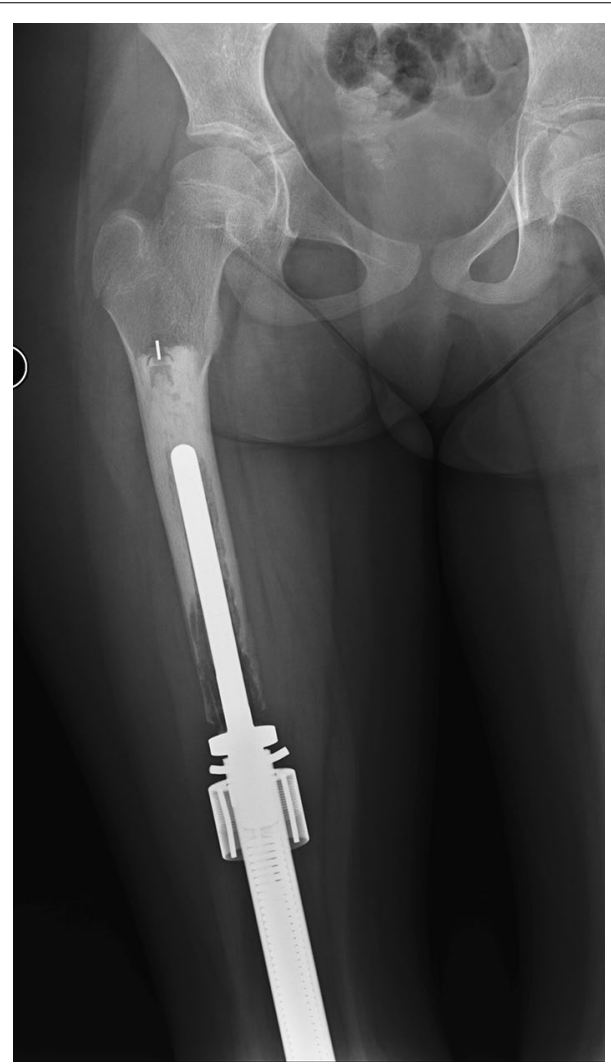

Fig. 4 Aseptic loosening of the proximal stem in a femoral endoprosthesis
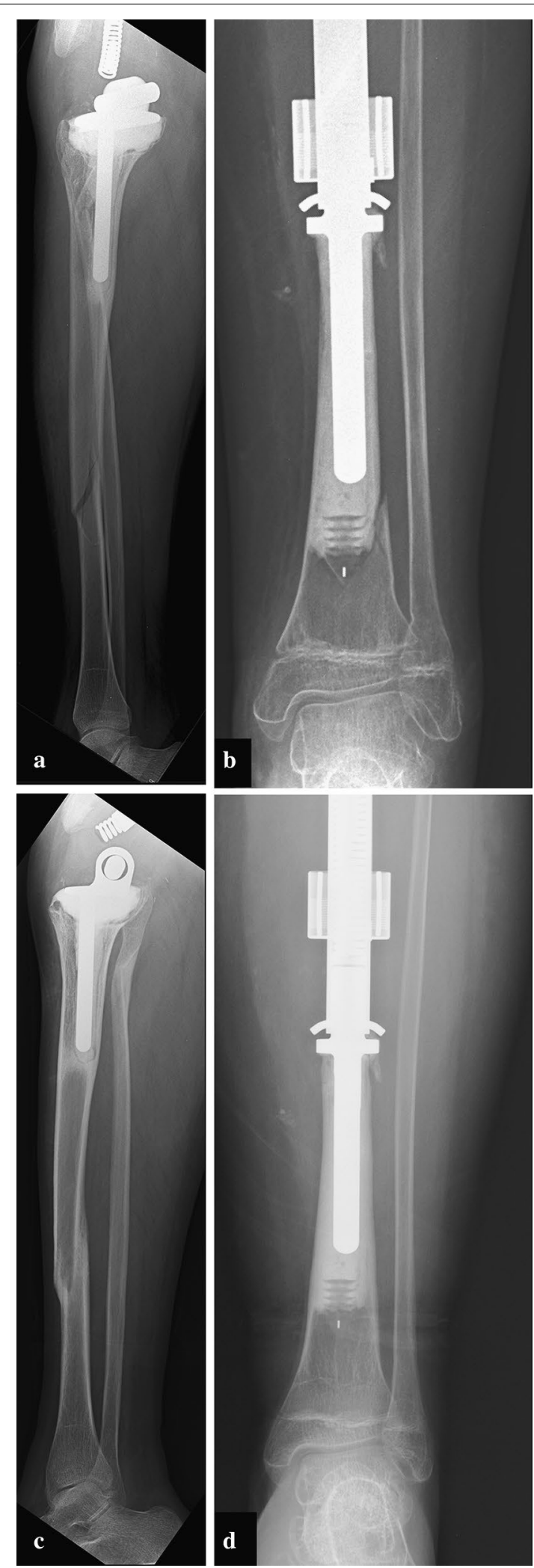

Fig. 5 Periprosthetic tibial fractures in patients with a distal femoral prosthesis $(\mathbf{a})$ and a proximal tibial prosthesis $(\mathbf{b})$ which healed with non-operative management $(\mathbf{c}, \mathbf{d})$ 


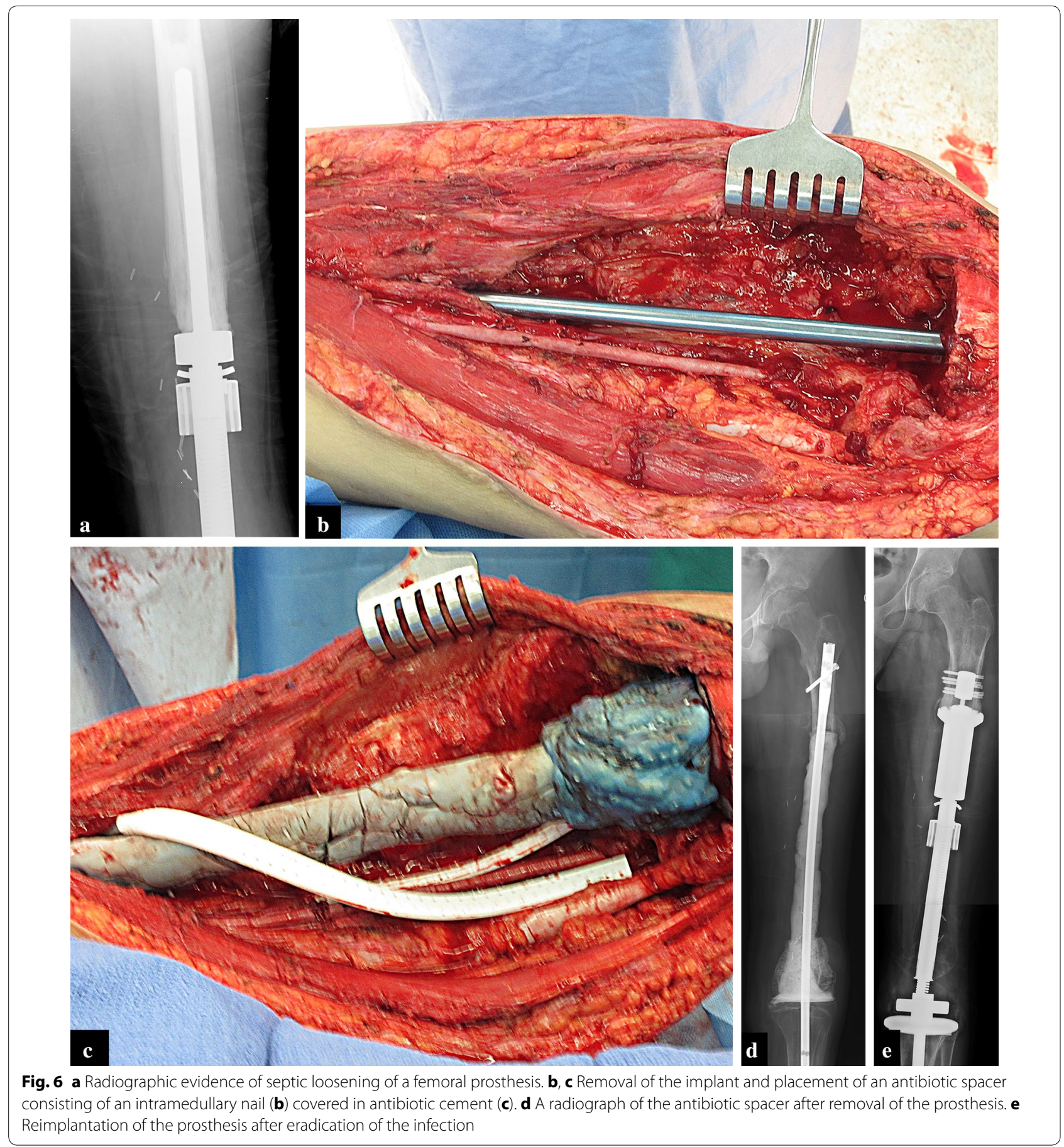

prostheses with a mean follow-up of 57 months. This is subject to all the inherent limitations of a retrospective study design. The results are comparable to previously published studies involving the Repiphysis ${ }^{\circledR}$ in terms of both function and complications. The overall limb-salvage rate was $95 \%$, with one patient requiring a hip disarticulation for an oncologic complication (local recurrence). On average, patients gained $9 \mathrm{~mm}$ of length per expansion and $4.6 \mathrm{~cm}$ per patient who has undergone lengthening. So far, those that reached skeletal maturity were lengthened by a mean of $7.4 \mathrm{~cm}$. To the author's knowledge, there has been no other non-invasive study with this amount of expansion and only one other series with greater reported mean expansion which used open 
lengthening techniques (Schiller et al. 1995). This is the largest study cohort of Repiphysis among similar published studies (Beebe et al. 2010; Cipriano et al. 2015; Gupta et al. 2006; Neel et al. 2003; Saghieh et al. 2010; Wilkins and Soubeiran 2001).

The mean MSTS score in this study was $80 \%$, which falls between the $67 \%$ and $90 \%$ MSTS scores reported in previous studies. There was only one case of limb length discrepancy, $2.5 \mathrm{~cm}$ limb length discrepancy in the humerus of patient 12 . The complication rate was $56 \%$ (15 complications in 27 prostheses); 2 type I, 4 type II, 5 type III, 3 type IV, and 1 type V. Our infection rate is comparable to previously published studies involving Repiphysis ${ }^{\circledR}$ and with both traditional invasively expandable endoprostheses, which have demonstrated an infection rate up to $18 \%$ (Wilkins and Soubeiran 2001; Saghieh et al. 2010; Cipriano et al. 2015; Hwang et al. 2012; Picardo et al. 2012).

A limitation of the Repiphysis ${ }^{\circledR}$ relative to the JTS is that the Repiphysis ${ }^{\circledR}$ requires conversion to a nonexpandable adult prosthesis at skeletal maturity while the JTS is designed to be a permanent implant. A limitation of the JTS relative to the Repiphysis ${ }^{\circledR}$ is that patients are unable to undergo an MRI. Given the value of MRI for restaging in this patient population, the use of devices that prohibit this imaging modality must be carefully considered (Heindel et al. 2014; Nascimento et al. 2014). Furthermore, it is not known whether a patient will be able to function with a pediatric size endoprosthesis in the long-term.

In conclusion, the Repiphysis ${ }^{\circledR}$ prosthesis (Microport Orthopedics, Arlington, Tennessee, USA) is an option for limb-salvage in skeletally immature patients and has similar drawbacks to other designs. It requires conversion to an adult prosthesis with a limb retention rate of $95 \%$ and has a mean lengthening of $7.4 \mathrm{~cm}$ at maturity. Given the complications associated with the use of this prosthesis, as well as other expandables, the authors caution against uninformed use and recommend full and complete disclosure of all other treatment options with patients and their families before surgery.

\section{Authors' contributions}

JB was involved in conception of study design, data analysis, and drafting and revising of manuscript. FP was involved with data analysis and drafting of introduction for manuscript. KB was involved with data analysis and review and revising of manuscript. KT and $\mathrm{J}$ was involved in data analysis and review of manuscript. JM was involved in study design and data analysis. SR was involved in data analysis and drafting of manuscript. All authors read and approved the final manuscript.

\section{Competing interests}

One or more of the authors (JB) has received funding from the Musculoskeletal Transplant Foundation, and has also received fees from Merete, Inc. and Implant Cast outside of the submitted work, and holds several patents and licensing fees with CreOsso LLC, all of which are detailed in the attached ICMJE disclosure form. The other authors certify that he or she has no commercial associations (e.g., consultancies, stock ownership, equity interest, patent/licensing arrangements, etc.) that might pose a conflict of interest in connection with the submitted article.

\section{IRB approval}

This study involves the collection of human data and as such has received Institutional Review Board (IRB) approval. The work presented in this study took place at Rutgers New Jersey Medical School, Newark, New Jersey.

\section{Informed consent}

Informed consent was carried out with patient and parents, which included the need for multiple surgeries, the complication rate of this procedure, and the need to exchange the implant to an adult implant when the patient reaches skeletal maturity.

Received: 13 August 2015 Accepted: 2 December 2015

Published online: 22 December 2015

\section{References}

Anderson M, Green WT, Messner MB (1963) Growth and predictions of growth in the lower extremities. J Bone Joint Surg Am 45-A:1-14

Baumgart R, Betz A, Schweiberer L (1997) A fully implantable motorized intramedullary nail for limb lengthening and bone transport. Clin Orthop Relat Res 343:135-143

Beebe K, Benevenia J, Kaushal N, Uglialoro A, Patel N, Patterson F (2010) Evaluation of a noninvasive expandable prosthesis in musculoskeletal oncology patients for the upper and lower limb. Orthopedics 33(6):396. doi:10.3928/01477447-20100429-17

Cipriano CA, Gruzinova IS, Frank RM, Gitelis S, Virkus WW (2015) Frequent complications and severe bone loss associated with the repiphysis expandable distal femoral prosthesis. Clin Orthop Relat Res 473(3):831-838. doi:10.1007/s11999-014-3564-3

Dimeglio A (2001) Growth in pediatric orthopaedics. J Pediatr Orthop 21(4):549-555

Eckardt JJ, Eilber FR, Dorey FJ, Mirra JM (1985) The UCLA experience in limb salvage surgery for malignant tumors. Orthopedics 8(5):612-621

Eckardt JJ, Kabo JM, Kelley CM, Ward WG, Asavamongkolkul A, Wirganowicz PZ, Yang RS, Eilber FR (2000) Expandable endoprosthesis reconstruction in skeletally immature patients with tumors. Clin Orthop Relat Res 373:51-61

Enneking WF, Dunham W, Gebhardt MC, Malawar M, Pritchard DJ (1993) A system for the functional evaluation of reconstructive procedures after surgical treatment of tumors of the musculoskeletal system. Clin Orthop Relat Res 286:241-246

Gupta A, Meswania J, Pollock R, Cannon SR, Briggs TW, Taylor S, Blunn G (2006) Non-invasive distal femoral expandable endoprosthesis for limb-salvage surgery in paediatric tumours. J Bone Joint Surg Br 88(5):649-654. doi:10.1302/0301-620X.88B5.17098

Hardes J, Gebert C, Hillmann A, Winkelmann W, Gosheger G (2003) Rotationplasty in the surgical treatment plan of primary malignant bone tumors. Possibilities and limits. Orthopade 32(11):965-970. doi:10.1007/ s00132-003-0550-y

Harvey WF, Yang M, Cooke TD, Segal NA, Lane N, Lewis CE, Felson DT (2010) Association of leg-length inequality with knee osteoarthritis: a cohort study. Ann Intern Med 152(5):287-295. doi:10.7326/0003-4819-152-5-201003020-00006

Heindel W, Gübitz R, Vieth V, Weckesser M, Schober O, Schäfers M (2014) The diagnostic imaging of bone metastases. Dtsch Arztebl Int 111(44):741747. doi:10.3238/arztebl.2014.0741

Henderson ER, Groundland JS, Pala E, Dennis JA, Wooten R, Cheong D, Windhager R, Kotz RI, Mercuri M, Funovics PT, Hornicek FJ, Temple HT, Ruggieri P, Letson GD (2011) Failure mode classification for tumor endoprostheses: retrospective review of five institutions and a literature review. J Bone Joint Surg Am 93(5):418-429. doi:10.2106/JBJS.J.00834

Henderson ER, Pepper AM, Marulanda G, Binitie OT, Cheong D, Letson GD (2012) Outcome of lower-limb preservation with an expandable endoprosthesis after bone tumor resection in children. J Bone Joint Surg Am 94(6):537-547. doi:10.2106/JBJS.I.01575 
Herzog R, Hefti F (1992) Problems and complications of leg lengthening with the Wagner apparatus. Orthopade 21(3):221-229

Holm I, Nordsletten L, Steen H, Follerås G, Bjerkreim I (1994) Muscle function after mid-shaft femoral shortening. A prospective study with a two-year follow-up. J Bone Joint Surg Br 76(1):143-146

Hwang N, Grimer RJ, Carter SR, Tillman RM, Abudu A, Jeys LM (2012) Early results of a non-invasive extendible prosthesis for limb-salvage surgery in children with bone tumours. J Bone Joint Surg Br 94(2):265-269. doi:10.1302/0301-620X.94B2.27536

Janovec M, Polách J (1990) Analysis of the results of femoral lengthening in 34 children and adolescents. Acta Chir Orthop Traumatol Cech 57(5):405-416

Jeys LM, Grimer RJ, Carter SR, Tillman RM (2005) Periprosthetic infection in patients treated for an orthopaedic oncological condition. J Bone Joint Surg Am 87(4):842-849. doi:10.2106/JBJS.C.01222

Kenan S, Lewis MM (1991) Limb salvage in pediatric surgery. The use of the expandable prosthesis. Orthop Clin North Am 22(1):121-131

Lewis MM (1986) The use of an expandable and adjustable prosthesis in the treatment of childhood malignant bone tumors of the extremity. Cancer 57(3):499-502

Mankin HJ, Fogelson FS, Thrasher AZ, Jaffer F (1976) Massive resection and allograft transplantation in the treatment of malignant bone tumors. $\mathrm{N}$ Engl J Med 294(23):1247-1255. doi:10.1056/NEJM197606032942301

Marcove RC (1976) The treatment of malignant bone tumors by conservative surgery. Recent Results Cancer Res 54:218-220

Nascimento D, Suchard G, Hatem M, de Abreu A (2014) The role of magnetic resonance imaging in the evaluation of bone tumours and tumour-like lesions. Insights Imaging 5(4):419-440. doi:10.1007/s13244-014-0339-z

Neel MD, Letson GD (2001) Modular endoprostheses for children with malignant bone tumors. Cancer Control 8(4):344-348

Neel MD, Wilkins RM, Rao BN, Kelly CM (2003) Early multicenter experience with a noninvasive expandable prosthesis. Clin Orthop Relat Res 415:72-81. doi:10.1097/01.blo.0000093899.12372.25

Palumbo BT, Henderson ER, Groundland JS, Cheong D, Pala E, Letson GD, Ruggieri $P$ (2011) Advances in segmental endoprosthetic reconstruction for extremity tumors: a review of contemporary designs and techniques. Cancer Control 18(3):160-170
Papaioannou T, Stokes I, Kenwright J (1982) Scoliosis associated with limblength inequality. J Bone Joint Surg Am 64(1):59-62

Picardo NE, Blunn GW, Shekkeris AS, Meswania J, Aston WJ, Pollock RC, Skinner JA, Cannon SR, Briggs TW (2012) The medium-term results of the Stanmore non-invasive extendible endoprosthesis in the treatment of paediatric bone tumours. J Bone Joint Surg Br 94(3):425-430. doi:10.1302/0301-620X.94B3.27738

Rougraff BT, Simon MA, Kneisl JS, Greenberg DB, Mankin HJ (1994) Limb salvage compared with amputation for osteosarcoma of the distal end of the femur. A long-term oncological, functional, and quality-of-life study. J Bone Joint Surg Am 76(5):649-656

Saghieh S, Abboud MR, Muwakkit SA, Saab R, Rao B, Haidar R (2010) Sevenyear experience of using Repiphysis expandable prosthesis in children with bone tumors. Pediatr Blood Cancer 55(3):457-463. doi:10.1002/ pbc.22598

Schiller C, Windhager R, Fellinger EJ, Salzer-Kuntschik M, Kaider A, Kotz R (1995) Extendable tumour endoprostheses for the leg in children. J Bone Joint Surg Br 77(4):608-614

Simon MA, Aschliman MA, Thomas N, Mankin HJ (1986) Limb-salvage treatment versus amputation for osteosarcoma of the distal end of the femur. J Bone Joint Surg Am 68(9):1331-1337

Song KM, Halliday SE, Little DG (1997) The effect of limb-length discrepancy on gait. J Bone Joint Surg Am 79(11):1690-1698

Stanitski DF (1999) Limb-length inequality: assessment and treatment options. J Am Acad Orthop Surg 7(3):143-153

Veenstra KM, Sprangers MA, van der Eyken JW, Taminiau AH (2000) Quality of life in survivors with a Van Ness-Borggreve rotationplasty after bone tumour resection. J Surg Oncol 73(4):192-197

Wilkins RM, Soubeiran A (2001) The Phenix expandable prosthesis: early American experience. Clin Orthop Relat Res 382:51-58

\section{Submit your manuscript to a SpringerOpen ${ }^{\circ}$ journal and benefit from:}

- Convenient online submission

- Rigorous peer review

- Immediate publication on acceptance

- Open access: articles freely available online

- High visibility within the field

- Retaining the copyright to your article

Submit your next manuscript at springeropen.com 